\title{
Rogue States? Reflexões sobre os Estados e a democracia a partir da desconstrução
}

\author{
Rogue states? Reflections about the States and \\ democracy from the deconstruction's perspective
}

\author{
Bruno Meneses Lorenzetto* \\ Katya Kozicki ${ }^{* *}$
}

\section{Resumo}

O artigo apresenta, a partir do marco teórico da desconstrução do filósofo Jacques Derrida, uma leitura das relações políticas entre os Estados democráticos e seus "inimigos", com a qualificação destes como "rogues". O Estado qualificado como "bandido" esconde o uso da razão do "mais forte", pois se tornou a designação que habilita estratégias de guerra, invasão e ocupação. Levar a democracia para o resto do mundo se tornou um imperativo, não importa a que custo. O problema é que essa acusação aos Estados que desrespeitam o Direito internacional se volta contra seus promotores. A partir disso, surge a necessidade de reelaboração dos conceitos de Estado, Estadonação, soberania nacional e cidadania.

Palavras-chave: Estado. Rogues. Soberania. Democracia.

\section{Abstract}

The article presents, from the theoretical landmark of deconstruction of the philosopher Jacques Derrida, a reading of the political relations between democratic states and their "enemies" with the qualification of these as "rogues". The state qualified as "bandit", hides the use of the reason of the "stronger"

\footnotetext{
Mestre em Direito das Relações Sociais e Doutorando em Direitos Humanos e Democracia pela Universidade Federal do Paraná. Professor da Pontifícia Universidade Católica do Paraná. Curitiba - PR - Brasil. Email: bruno_lorenzetto@yahoo.com.br

* Mestre em Teoria e Filosofia do Direito e Doutora em Direito, Política e Sociedade pela Universidade Federal de Santa Catarina. Professora Titular da Pontifícia Universidade Católica do Paraná e Professora Associada da Universidade Federal do Paraná. Bolsista de Produtividade em Pesquisa do CNPq. Curitiba - PR - Brasil. Email: kkozicki@uol.com.br
} 
because it became the designation that enables strategies of war, invasion, occupation. Bringing democracy to the rest of the world has become an imperative, no matter what it costs. The problem is that this accusation, facing the states that disrespect the International Law turns against its own promoters. From this arises the need of rethinking the concepts of State, Nation-State, national sovereignty and citizenship.

Keywords: State. Rogues. Sovereignty. Democracy.

\section{Introdução}

O presente trabalho procura desconstruir, a partir das sendas apontadas pelo filósofo Jacques Derrida, a designação, que se tornou recorrente na década de 1990 e teve continuidade nos anos 2000, de Estado "bandido" - "rogue', "voyou" ou "Schurke". Esse é o seu objeto. Em verdade, o seu objeto sorrateiro, que se coloca na espreita, não é tanto o Estado, mas o nome/adjetivo "rogue", "bandido".

Mas qual seria a importância de dedicar algum tempo, mesmo que um tempo "deslocado", para um nome que também é uma designação, uma qualificação? A própria tarefa da desconstrução já aponta nesse sentido. Não se trata, por isso, de trabalhar apenas com conceitos já desenvolvidos na tradição, dotados de largo espectro histórico. Pois aquilo que guia essa reflexão é o não acabamento, a impossibilidade estrutural e seus bloqueios.

A postura desconstrutiva indica, então, que pode existir um potencial no subalterno, na marginalidade, pois, no caso, se a designação fizesse referência apenas a uma impressão, que acaba por ser recorrente de uma nação sobre a outra em contextos culturais - ou seja, que a outra nação é "selvagem", para não dizer "bárbara", desconstituída, em seu discurso, de sua capacidade de se manifestar ${ }^{1}$ -, seria compreensível ante o projeto transbordante do Estado-nação

Derrida (2002a) lembra que a ausência da linguagem constituiria a essência da animalidade. 
de consolidar violentamente uma identidade nacional e, na medida do possível, colonizar outras nações com essa mesma identidade.

O problema é que o uso do termo "rogue" - e, ao que tudo indica, sua maior expressividade parte de maneira vinculada à língua inglesa por razões estratégicas - ganhou proporções significativas quando ultrapassou as margens gramaticais ou do juízo subjetivo de alguns para se tornar justificativa, fundamento, razão, para que atos bélicos viessem a se desenvolver ao longo dos últimos anos. Em suma, a "caça" aos "bandidos" teve início e o argumento para a ação foi justamente esse nome (substantivo), esse adjetivo. Importa, por isso, uma análise sobre a pluralidade de significados que o termo pode vir a ter em diferentes línguas, já que, como lembra Derrida (1973, p. 8): "Não há significado que escape, mais cedo ou mais tarde, ao jogo das remessas significantes, que constitui a linguagem".

Assim, o jogo (das remessas) apaga o limite, a margem a partir da qual se acreditou que podia ser realizada a regulação da circulação dos signos. E, no jogo da diferença, os nomes próprios já não são nomes próprios, pois sua produção implica seu esquecimento. Não há uma inscrição própria, "[...] porque o nome próprio nunca foi, como denominação única reservada à presença de um ser único, mais do que o mito de origem de uma legibilidade transparente e presente sob a obliteração [...]" (DERRIDA, 1973, p. 134). Derrida (1973, p. 138-139) entende que o nome próprio nunca foi possível, a não ser pelo seu funcionamento em uma classificação, em uma cadeia de diferenças:

Nomear [...] tal é a violência originária da linguagem que consiste em inscrever uma diferença, em classificar, em suspender o vocativo absoluto. Pensar o único no sistema, inscrevê-lo neste, tal é o gesto da arquiescritura: arquiviolência, perda do próprio, da proximidade absoluta, da presença de si, perda na verdade do que jamais teve lugar, de uma presença de si que nunca foi dada mas sim sonhada e desde sempre desdobrada, repetida, incapaz de aparecer-se de outro modo senão na sua própria desaparição. 
Por isso, outro problema que se endereça é o da própria tradução. Tradução necessária nos meios midiáticos para se compreender o fenômeno de um país como os Estados Unidos chamar outro de "rogue", assim como a tradução intralinguística, ao procurar os sentidos que se escondem no signo. Vale lembrar: aquilo que a multiplicidade de idiomas limita não é apenas uma tradução "verdadeira", uma entre-expressão transparente e adequada, mas também uma ordem estrutural, uma coerência da construção (DERRIDA, 2002b).

Assim, "rogue" designa: velhaco, embusteiro, tratante, enganador, mentiroso; pessoa malévola, elemento nocivo; vagabundo, malandro, vadio; uma pessoa desonesta ou imoral; uma pessoa que brinca e se comporta de uma maneira que não é aprovada, mas que não é criticada por gostarem dela ou por ser inofensiva; um animal feroz, selvagem, perigoso, que se separa do resto de seu grupo, em especial um elefante que se separa da manda; planta intrusa ou inferior. Ao passo que "rogue's gallery" trata da coleção de fotografias de criminosos mantida pela polícia. "Roguery" significa velhacaria, patifaria, maroteira, malandragem. "Rogue's march" ocorre com o rufar dos tambores que acompanha a expulsão de soldados indignos de sua unidade. Em francês, "voyou" também remete àquele que é vagabundo, malandro, ou seja, uma espécie de "bandido".

De acordo com Hobsbawm (2003), os bandidos, por definição, são aqueles que resistem à obediência, estão fora do alcance do poder. Constituem, eles mesmos, fontes potenciais do poder e, portanto, de rebeldia. De fato, o significado (italiano) original da palavra bandito é uma pessoa "declarada fora da lei" por qualquer motivo, ainda que não seja estranho que os foragidos se convertessem em ladrões.

A ampla gama de sentidos - em alguns casos, opostos - dos signos serve como referencial para a desconstrução, pois esta tem como escopo desestruturar discursos que se apresentem como "naturais" e procura mostrar a metafísica subjacente nas instituições que organizam a sociedade. Não se apresenta como esquema analítico universalizável; ao contrário, procura desnaturalizar, desestabilizar as propriedades estruturais de cada "construção" específica. Não é, porém, uma 
"destruição", e sim uma posição que enfatiza a disseminação de sentidos que um signo pode supor. No caso em questão, procura mostrar que as bases discursivas que permitem que o Estado acusador manifestese contra o acusado são favorecidas por determinada organização de poderes no plano internacional, mas essa mesma composição narrativa pode ser voltada contra o acusador, ainda que ela esbarre na lógica dos poderes estabelecidos.

Logo, trabalha com pares problematizando-os, pois, de uma parte, tudo aquilo que não entra na relação (dentro e fora) de um par de opostos é marginalizado ou suprimido. Em outros termos, a tessitura de uma rígida dualidade pressupõe, em seu arcabouço, uma hierarquia que nem sempre se apresenta de tal forma. O caso das relações internacionais acaba por evidenciar essa edificação hierárquica silenciosa. Por mais que organismos internacionais procurem definir a isonomia formal dos atores políticos internacionais, no plano material, ela encontra dificuldades de ser observada.

Assim, aquilo que a desconstrução possibilita passa pela identificação de uma dualidade, de um campo teórico, pelo diagnóstico da hierarquia dos pares e, por fim, indica a possibilidade de sua subversão, ao mostrar que aquelas categorias colocadas na base poderiam estar no topo e vice-versa, como explana Bennington (1996, p. 79):

Pode-se anunciar desde então que toda filosofia que faz passar mundo e linguagem por dois reinos separados por um abismo a se atravessar permanece presa, no ponto mesmo da pretensa travessia, ao círculo do dogmatismo e do relativismo que ela não teria meios de romper, daí resulta ao menos: - que é necessário repensar todas as oposições que vêm a dar no par sujeito/objeto, a partir de um je(i)to mais radical; - que todas as determinações da linguagem (até mesmo do simbólico) estão delimitadas (senão transgredidas); - que a definição da humanidade (com relação à animalidade e/ou ao divino) é posta em dúvida, assim como a do animado com relação ao inanimado, e principalmente às máquinas, à tekhnè em geral; - que não existe fora-texto. 
Vale lembrar que o próprio termo "desconstrução" é proposto como tradução da "Destruktion" heideggeriana, mas que, por sua vez, institui em sua flexão uma originalidade, uma tradução suplementar. Aquilo que seria intraduzível por excelência seria o nome próprio. Mesmo ante uma multiplicidade de línguas em situação de tradução entre si, aquilo que elas guardariam como próprio, característico, seriam os nomes próprios, que dispensam tradução, pois almejam uma posição de universalidade de referência (BENNINGTON, 1996). O problema é que essa unidade de sentido, uma semântica final, acaba por ser articulada com outros mecanismos ou acordos estratégicos que procuram definir aquilo que é natural.

Derrida (2002b) lembra que no episódio de Babel, Deus impõe a necessidade e a impossibilidade da tradução; a necessidade de tradução sem alcançar a tradução perfeita, final, a língua única - o monolinguismo². A mesma impossibilidade traz o termo "bandido", em sua imperfeição e parcialidade, pois não pode e não consegue contemplar todo o espectro semântico de "rogue" e "voyou", assim como estes também não correspondem à possibilidade produtiva e criativa de novas referências ao se usar o termo em português - bandido. Logo, a partir da perfectibilidade que a desconstrução sinaliza, a questão que se coloca é: quais Estados são "bandidos"? Quem os designa? Quem possui o poder de acusar - qual o fundamento ou a origem desse poder - e, por consequência, detém a legitimidade para utilizá-lo, ou se trata apenas de uma questão de força, da lei do mais forte?

\section{Estados "bandidos"?}

De acordo com Heller (2002), a pós-modernidade possui, em todos os sentidos, inclusive no campo político, duas faces, assim como Janos. O embotamento, enfraquecimento e, algumas vezes, desaparecimento dos roteiros de classes e a ascendência do caráter funcionalista da

Segundo Ricoeur (2009, p. 21): "As zonas de intradutibilidade estão disseminadas no texto, e fazem da tradução um drama, e do desejo de uma boa tradução um desafio". 
sociedade contribuíram enormemente, segundo a autora, para a reorganização e a "modernização" dos tradicionais padrões e programas políticos.

Entende Heller (2002) que a compreensão recorrente do Estado como uma espécie restrita de "agência de classe", ou seja, artifício limitado a promover os interesses de uma classe específica, teve de ser substituída por concepções mais sofisticadas, pois o simples alinhamento "classe contra classe" na arena política abriu espaço para diagnósticos mais complexos. Essa reconceitualização, por sua vez, contribuiu de maneira muito significativa para a esquerda, pois esta passou a levar muito mais a sério o Estado e, acima de tudo, todas as instituições democráticas. Isso pode ser percebido com as mudanças dos discursos, não mais no sentido de um uso estratégico da democracia para a dominação do poder e realização do projeto comunista, mas de formas diluídas dessa retórica e da adoção - eis que não lhe era naturalmente dado - da democracia como valor guia.

A intensidade da retórica em torno da democracia fez com que partidos conservadores também procurassem utilizar esta como signo de oposição a ditaduras que se procuraram construir em nome do proletariado. A democracia se torna, dessa forma, um signo esvaziado, uma casa que pode ser habitada por ideologias distintas. Pode-se, inclusive, formar consensos sobre o signo, sobre o poder do povo, ainda que os fundamentos e os outros valores das partes que concordam sobre a democracia continuem tensionados. A partir disso, o caminho - ao menos no Ocidente - se faz rumo à democratização. Mas em que língua? Sob que regras? Deve a democracia possuir uma força que a promova para outros países?

Algumas respostas podem ser tecidas, mas não sem enfrentar algumas questões. De acordo com Derrida (2005), ante a soberania do Estado, do Estado-nação, do rei, ou, em uma democracia, do povo, a ipseidade, a unicidade do ente, aquilo que o distingue de todos os demais, é próprio de um determinado Estado, é o princípio da soberania legítima, é a supremacia reconhecida ou acreditada de um poder ou de 
uma força, de um kratos. A ipseidade se torna fonte suprema da razão do mais forte como direito, da força garantida ao direito:

[...] democracia seria precisamente isto, uma força (kratos), uma força na forma de uma autoridade soberana (soberana, ou seja, kurios ou kuros, detendo o poder para decidir, para ser decisivo, para prevalecer, ter razão sobre ou prevalecer sobre e dar a força de lei, kuroo), e logo o poder e a ipseidade do povo. Esta soberania é uma circularidade, de fato, uma esfericidade (DERRIDA, 2005, p. 13).

Há procura por uma circularidade; a formação de uma identidade entre a origem e a conclusão, a causa motriz e a causa final. Tocqueville (1988) circunda a mesma questão. Segundo ele, o princípio da soberania do povo teve, nos Estados Unidos, todas as repercussões práticas que uma imaginação poderia criar. Ele afirma que o povo, em corpo, é aquele que produz as leis, "como em Atenas", sendo representados por deputados.

Outra característica seria a de que o poder, nos Estados Unidos, estaria unificado e incorporado na sociedade. Tocqueville (1998) afirma que, em certos países, um poder atua sobre o corpo social de maneira exterior e o conduz em certo caminho. Em outros, a força seria divida na sociedade e fora dela. Contudo, nos Estados Unidos, o povo teria participação política intensa na composição das leis, na escolha do Legislativo e do Executivo. Assim, o povo governaria a si mesmo, de forma que a administração teria uma força restrita, marcada por sua origem popular e obediente ao poder de onde provinha.

Desse modo, a circularidade aparece: "O povo reina sobre o mundo político americano como Deus sobre o universo. Ele é a causa e o fim de todas as coisas. Tudo provém dele e tudo nele se absorve" (TOCQUEVILLE, 1998, p. 68). Sinais, pré-dicções de eventos que estariam, por assim dizer, por-vir, eis que a democracia e a "América" são os objetos em jogo, colocados em jogo.

Além da democracia na América, um importante fundamento para a definição das relações internacionais foi o legado da Paz de 
Westphalia. Se a democracia é o valor a ser adotado internamente e exportado como fonte da iluminação, como razão para os outros países, Westphalia representa a estrutura política e normativa das relações entre os Estados. Trata-se do conjunto de valores que definem as formas de troca de informações entre os Estados.

Teve-se, então, a reunião de princípios que definiram Westphalia ${ }^{3}$. O reconhecimento explícito da soberania (com ênfase, na época, na questão territorial) como fundamento para as relações entre os Estados, a restrição a intervenções em temas próprios de cada Estado em sua esfera interna e, ainda, o primeiro esboço da afirmação de uma igualdade jurídica formal entre os Estados no âmbito internacional.

O não intervencionismo nos assuntos internos de cada Estado demandava a aceitação de diferentes regimes de governo a serem adotados pelos Estados. Esse é, então, o princípio que enfrenta sua maior distensão, pois as justificativas para declarar guerra ou intervir precisariam ser justificadas pela iminência de uma ameaça ou pela retaliação a um ataque. Circunstâncias que, faticamente, nem sempre encontram o devido conteúdo probatório para justificar uma ofensiva militar. Ademais, Westphalia pressupunha a tolerância e a liberdade religiosa, o que apontava para uma formação secular das relações internacionais, a qual viria a substituir, parcialmente, o ideal de uma autoridade religiosa universal como mediadora dos conflitos entre cristãos.

A Paz de Westphalia contribuiu, assim, para a formação de um vazio na instância última de poder internacional, espaço no qual as ambiguidades entre acusador e acusado podem ser encontradas. Pois ao lado da demanda dos Estados por seu direito de existência

De acordo com Beaulac (2004), Westphalia funciona como um mito. Trata-se, para o autor, do primeiro caso em que a soberania dos Estados foi reconhecida e aplicada como um mito, o qual carregou grande poder ao longo dos anos por ser atrelado a um sistema racional e, ao mesmo tempo, ser observado como a fundação do sistema internacional de relação entre os Estados. Para Beaulac, Westphalia se tornou o signo mitificado de uma nova realidade, associada à igualdade soberana dos Estados. 
e necessidade de reconhecimento da sua soberania por Estados estrangeiros, também pode ser observada uma linha tênue entre os Estados que são "rogues" e aqueles que não são considerados como tal. A demanda imperativa por democracia e a adoção de outros valores caros ao Ocidente deixa de ser ponto de inflexão se o alinhamento econômico é mantido.

O Estado "bandido", "rogue", "voyou", esconde a razão do mais forte, uma questão de Direito, da força de lei, da ordem (mundial), do sentido e da direção do mundo. Pois o termo "voyou/rogue" se tornou, nos últimos anos, a mediação que permitiu estratégias de guerra contra o "eixo do mal" e o terrorismo internacional pelos Estados Unidos e seus aliados, através da denúncia de Estados "bandidos" (DERRIDA, 2005). Estados ambivalentes, incontroláveis, delinquentes, traiçoeiros, "roué", sem princípios ou moral, que não respeitam nenhuma lei. Não se sabe qual comportamento esperar deles. Em suma, malignos, maléficos, sorrateiros, enganadores, mas também "astutos".

Contudo, o poder não apenas de nomear, mas também de definir uma característica própria de uma pessoa, sua qualidade, a indicação de que alguém é um "bandido" parte de uma atribuição, uma categoria, uma classificação, um rol, uma acusação. Constitui uma denúncia, um veredicto, o qual justifica uma sanção. De acordo com a interpretação de Derrida (2007), tal definição permite que o Estado "bandido" possa ser punido, reduzido a um Estado inofensivo, se preciso, pelo uso da força (de lei).

O problema é que a definição de uma acusação precisa pressupor a organização de instituições normativas que definam os papéis de quem tem o poder de dizer o Direito, definir qual é a lei internacional, traçar qual conjunto normativo foi violado e, como consequência, utilizar a coerção como resposta racional para a ofensa realizada pelo acusado. Pressupõe-se, por isso, papéis que possam ser atribuídos a diferentes atores políticos internacionais. O paradoxo está na possibilidade de o acusador e o acusado demandarem o mesmo papel - com isso, pode-se perceber o funcionamento de uma hierarquia material nas 
relações internacionais. E, como afirma Derrida (2005), é apenas na modernidade pós-kantiana que o problema e, antes de tudo, a definição da democracia passa a ser enraizada no terreno turbulento das relações entre os Estados, em questões de guerra e paz ${ }^{4}$.

A questão de uma democratização universal, internacional, interestadual e, em especial, trans-estatal, permanece um tema cinzento. Mesmo a demanda kantiana de uma "majestade do povo", da soberania do povo, é, segundo Derrida, bastante complicada, pois majestas sempre foi o sinônimo de soberania. Apenas um Estado pode ser ou possuir soberania. Uma liga de povos não pode se tornar um Estado de povos ou ser unida em um único Estado (DERRIDA, 2005). ${ }^{5}$ O dilema está na utilização de uma estrutura conceitual definida para apenas um ente político, para a vinculação de uma pluralidade de Estados.

A proposta de extensão da democracia para além da soberania Estado-nacional, além da cidadania, demandaria: "[...] a criação de um espaço jurídico-político internacional que, sem acabar com toda a referência à soberania, nunca pararia de inovar e inventar novas distribuições e formas de compartilhar, novas divisões de soberania" (DERRIDA, 2005, p. 87).

Contudo, na interpretação de Mouffe (1999), aquilo que importa para Carl Schmitt (referência?) na conceituação de democracia é a possibilidade de traçar uma linha de demarcação entre aqueles que pertencem ao demos e, por isso, possuem direitos iguais, e aqueles que, no campo político, não podem estar protegidos pelos mesmos direitos iguais, pois não fazem parte do demos. Assim, uma "democracia da humanidade" seria uma pura abstração, pois a igualdade apenas pode existir em termos específicos e em esferas determinadas.

4 Para Renan (1987, p. 61): "As nações assim entendidas são algo bastante novo na história. A antiguidade não as conheceu; Egito, China, a antiga Caldéia, não foram de modo algum nações. Eram manadas conduzidas por um filho do Sol o um filho do Céu. Não houve cidadãos egípcios, do mesmo modo que não existem cidadãos chineses. A antiguidade clássica teve repúblicas locais e reinos municipais, confederações de repúblicas locais e impérios; mas não teve nações no sentido que nós as entendemos".

5 Cf. Kant (1988). 
Ademais, o conceito central de democracia não se refere à humanidade, mas a um povo, de tal forma que não pode haver uma democracia da humanidade como os liberais a projetam - esta seria um oxímoro. Resta, então, o aviso de Mouffe (1999, p. 43) para quem acredita que o processo de globalização formaria a base para uma democratização universal e estabeleceria uma cidadania cosmopolita: "[...] a identidade de uma comunidade política democrática depende da possibilidade da demarcação de uma fronteira entre 'nós' e 'eles', Schmitt sublinha o fato de que a democracia sempre envolve relações de inclusão-exclusão".

A proposta de democracia em que pensa Derrida, lembra Kozicki (2005), não é uma democracia realizada aqui e agora, mas que assume a forma de uma possibilidade, como uma abertura perante o futuro. $\mathrm{Ou}$ seja, tanto a justiça como a democracia seriam representações que fugiriam ao aqui e agora, escapando ao presente e ao acabamento, pois representam sempre algo que está sempre por-vir, por acontecer. Nesse sentido, afirma Derrida (2005, p. 87):

A democracia é o único sistema, o único paradigma constitucional, no qual, em princípio, se possui ou assume o direito de criticar tudo publicamente, inclusive a ideia de democracia, seu conceito, sua história, e seu nome. Inclusive a ideia de paradigma constitucional e da absoluta autoridade da lei.

Assim, a promessa, o por-vir, não apenas aponta para a dificuldade do acabamento, da completude, do fechamento, de uma existência presente acabada, como para uma estrutura permanentemente aporética, aberta, criticável, perfectível.

Aquilo que Derrida (2005) defende como uma "Nova Internacional", em sua obra Espectros de Marx, procura apontar na direção de que, mesmo a Declaração Universal dos Direitos Humanos, renovada no final da Segunda Guerra Mundial, continua a fazer uma referência, a ser dependente de instituições de Direito internacional, em especial das Nações Unidas. Porém, essa referência se encontra em contradição com o princípio de soberania do Estado-nação moderno: 
Meu subtítulo 'a nova Internacional' se refere a uma transformação profunda, projetada sobe um largo período, do direito internacional, de seus conceitos e de seu campo de intervenção. Assim como o conceito de direitos humanos foi determinado lentamente no transcurso dos séculos através de múltiplos abalos sociopolíticos [...], o direito internacional deveria estender e diversificar seu campo até incluir nele, se ao menos deve ser consequente com a ideia da democracia e dos direitos humanos que proclama, o campo econômico e social mundial, para além da soberania dos Estados [...] (DERRIDA, 2003, p. 98).

De acordo com Skinner (2000), em Espectros de Marx, a espectralidade constitui o viés estratégico que a desconstrução assume desde a experiência do indecidível. Derrida (2003) promove o retorno de Marx, estruturando mais uma cadeia textual do discurso desconstrutivo, uma espectografia.

Então, forma-se uma remissão ao espectro, à assombração, ao fantasma, à aparição, e esse jogo não permite que se atribua uma identidade, um nome definitivo ao espectro. O espectro, por não ser o morto nem o vivo, nem o corpo nem a alma, nem o dentro nem o fora, nem o presente nem o passado, habita dois mundos. Desse modo, a aparição espectral surge como elemento que envolve dois termos ao mesmo tempo.

O aspecto "normativo" da referida obra de Derrida (2003) se encontra na proposta de reelaboração profunda e crítica dos conceitos de Estado, Estado-nação, soberania nacional e cidadania, que não seria possível sem a referência a uma problemática marxista: "[...] as conclusões marxistas sobre o Estado, o poder do Estado e o aparato de Estado, sobre as ilusões de sua autonomia de direito sobre forças sócioeconômicas, mas também sobre as novas formas de uma decadência [...]" (DERRIDA, 2003, p. 109). A tarefa, então, que Derrida (2003) propõe é a de se (re)pensar as categorias elencadas, além de refletir sobre a questão do nome: o que acontece hoje "em nome" da democracia? 


\section{Ainda existem Estados "bandidos"?}

Um dos possíveis sentidos da tradução de "rogue" é a referência a um animal selvagem desgarrado. Assim, qualquer animal (ou mesmo uma planta) pode ser nominado de "rogue", como bandidos que assolam e violam costumes, práticas e convenções da própria comunidade.

A qualificação e predição de "bandido" se faz como uma marca, uma classificação que separa algo. Uma marca que discrimina, uma marca de infâmia, que bane ou exclui, mas também pode trazer o julgado diante da lei (before the law). No reino animal, anota Derrida (2005), "rogue/voyou" é aquele animal que nasce de maneira diferente, não se mistura com a horda e pode atacar a qualquer momento, sem aviso prévio. Por isso, a adoção pelos Estados Unidos do termo "rogue state" (Estado "bandido") serviu para denunciar os Estados "inimigos" em um cenário que se forjava unipolar após a Guerra Fria, ou seja, com apenas uma potência a dominar o mundo multipolar.

Durante o governo de Bill Clinton, em referência àquilo que já era chamado de terrorismo internacional, o termo foi utilizado e estendido para qualquer país que violasse as regras de Direito internacional. A denúncia de Estados "bandidos" se tornou mais pronunciada. A frase se tornou corrente, em alguns casos, substituída por outlaw (fora da lei) ou pariah (pária).

E foi em meio a esse cenário que Noam Chomsky lançou o livro Rogue States: The Rule of Force in World Affairs, no qual afirma que os Estados mais bandidos são justamente aqueles que usam conceitos como "Estados bandidos" na retórica, no discurso jurídico, com consequências estratégico-militares previamente definidas. Logo, os primeiros e mais violentos dos Estados "bandidos", na acepção de Chomsky, são aqueles que ignoram e continuam a violar o Direito internacional que dizem proteger. O Direito em nome do qual falam acaba por se tornar o mesmo conjunto normativo a partir do qual declaram guerra.

A partir disso, um Estado "bandido" passou a ser aquele que os Estados Unidos identificam como tal. Desse modo, o primeiro regime 
a ser tratado como "bandido" foi o governo de Noriega, no Panamá. Em 1998, o Iraque se tornou um Estado "bandido" e Saddam Hussein foi chamado de "a besta de Bagdá", depois de ter sido, assim como Noriega, um aliado de longa data e um parceiro econômico (DERRIDA, 2005).

Outros exemplos de Estados "bandidos" são: Líbia, Sudão, Cuba, Nicarágua, Coreia do Norte e Irã. O cenário é móvel. Desde o final da Guerra Fria e com o "11 de setembro", o Afeganistão passou de inimigo da União Soviética a inimigo dos Estados Unidos. Existem transições políticas na ordem mundial, as quais, em larga medida, tornam-se dependentes do poder dos Estados Unidos. Poder que se apresenta como árbitro no âmbito internacional dos conflitos, com sua presença dominante no Conselho de Segurança da ONU e em outras instituições internacionais, como observa Derrida (2004, p. 104):

Mesmo quando - e com impunidade - eles não respeitam o espírito ou a letra dessas instituições e de suas resoluções. Os Estados Unidos detêm o poder de acreditar, diante do mundo, uma certa auto-representação: eles representam a suposta unidade final de força e lei, da maior força e do discurso da lei. ${ }^{6}$

A denominação "Estado bandido" se coaduna com o fato de que, a partir de então, a ameaça total não vem mais de um Estado, mas de forças anônimas, imprevisíveis, incalculáveis. Não se trata mais de um mundo bipolar, de uma ameaça nuclear proveniente do embate entre duas potências mundiais, mas de se colocar em risco a "existência do mundo", pois se procura que este se transforme em unipolar, ainda que as relações internacionais apontem para a construção de diferentes discursos no cenário internacional e a articulação de diferentes poderes aponte para a multipolaridade.

\footnotetext{
6 Inserida nesse contexto, não parece ser tão estranha a seguinte afirmação de Derrida (2007, p. 34): "Houve, há ainda, na espécie humana, muitos 'sujeitos' que não são reconhecidos como sujeitos, e recebem este tratamento do animal [...]".
} 
Por isso, com o "11 de setembro", segundo Borradori (2004), ficou exposta a ordem mundial, pois os Estados Unidos, em seu papel de potência tecnocientífica, capitalista e militar, passou a simbolizar a própria ordem mundial, a legitimidade da lei internacional e da diplomacia, além do poder da mídia ${ }^{7}$.

Logo na sequência dos acontecimentos do "11 de setembro", o Secretário de Defesa, Paul Wolfowitz, defendeu que os Estados Unidos deveriam atacar Basra e os campos de petróleo do sul do Iraque. Na época, suas propostas foram recusadas, mas depois ele foi acompanhado por outros oficiais do governo, que buscavam mudar a doutrina dos Estados Unidos em suas relações internacionais.

O presidente George W. Bush, usando das alegações falsas de que existiam armas nucleares, biológicas e químicas no Iraque, mobilizou seu país para a guerra que ocasionou a ocupação do Afeganistão. 0 problema estava no fato de que a existência de um programa de armas e a importação de urânio da Nigéria não puderam ser provadas, enquanto as inspeções realizadas pela ONU indicavam a inexistência de armas químicas ou biológicas, do seu uso ou de qualquer estoque. Bush estava usando o passado do Iraque para declarar guerra ao país que, na década de 1980, havia usado armas químicas em diversas ocasiões contra seus inimigos e, em 1988, realizou o ataque à cidade de Halabja contra os curdos, no fim da guerra entre Irã e Iraque.

A legalidade de um ataque armado contra o Iraque não foi um fator decisivo nos debates sobre a guerra, ao passo que o governo Bush não se preocupou em elaborar argumentos jurídicos sólidos que justificassem a ofensiva bélica contra o país. Como dispõe o artigo 2, item 4, da Carta da ONU, seus membros deverão evitar ameaças ou o uso da força contra a integridade territorial de outros Estados, com o limite do direito à autodefesa, preservado no artigo 51 da Carta. Esta, que é obrigatória para os seus membros, é reconhecida como a fundadora de uma nova fase na regulamentação do uso da força pelos Estados.

Ver também a análise realizada por Agamben (2005). 
A ideia dos criadores da Carta da ONU era a da manutenção da integridade territorial e a independência política (já presentes em Westphalia) para todos os Estados soberanos. De acordo com Bhuta (2003), a postura e os pronunciamentos realizados pelo governo Bush levaram a uma perspectiva de que, na ordem internacional, o Direito se tornou apenas uma consideração política a ser resolvida com outras; não se tratava de uma obrigação compulsória, apenas quando estava voltada para o inimigo, cujos atos de ilegalidade precisariam ser repreendidos de maneira feroz.

Os limites da legalidade aos quais um inimigo é sujeitado não se aplicam aos Estados Unidos, cujo poder permite que o Estado arrogue para si a titularidade para determinar as fronteiras entre 0 Direito enquanto princípio e o Direito enquanto meio coercitivo. Nesse ponto, apresenta-se a ambivalência do estar-fora-da-lei. Pois, o forada-lei pode representar, por um lado, aquele que está acima das leis, o soberano, ou tomar a forma da própria lei, do Direito, da fonte normativa, de garantidor das leis; porém, por outro lado, o fora-da-lei situa o local em que a lei não aparece, não se apresenta, não é aplicada e não é respeitada (DERRIDA, 2009).

O interessante é que o veredicto feito correntemente na retórica política de que certos Estados não respeitam o Direito internacional são "bandidos", criminosos, ficam à margem da civilidade internacional, violam propriedades, fronteiras e regras de conduta internacional, inclusive as leis de guerra, é uma acusação que se volta contra seus promotores. A "sentença", escrita em inglês, volta-se contra seu escritor, os Estados Unidos. Por isso, os Estados acusados de se comportarem como "bandidos" devolvem a acusação contra seu promotor e alegam, por sua vez, que os verdadeiros Estados "bandidos" são as nações soberanas, hegemônicas e poderosas, que são as primeiras a desrespeitar o Direito internacional.

Se é possível observar que os Estados "bandidos" são aqueles que, em processo sumário, nem sempre composto com as devidas provas - basta pensar nos motivos, falsos, que levaram os Estados 
Unidos a invadirem o Iraque -, os Estados Unidos dizem que o são, ou seja, aqueles que são nomeados como tais pela nação que se arroga garantir a ordem mundial, então, a acusação, sem maiores problemas, pode ser voltada para o nomeador, para o acusador, o classificador.

Os Estados Unidos, portanto, fonte de segregações autointeressadas, tais como o "eixo do mal", podem ser vistos como o mais "bandido/selvagem/rogue/voyou" de todos os Estados, aquele que mais constantemente viola o Direito internacional, e, por ser aquele que o deveria sustentar, é o que o utiliza da maneira mais displicente. A saída normativa para tal situação ambivalente levaria, possivelmente, a outros jogos entre o positivo e o negativo, a hibridações, pois demandaria que a produção de regras internacionais fosse realizada de forma democrática entre os Estados. Isso só seria possível com o resgate do conceito kantiano de Federação, mas deixaria sem resposta o problema da decisão executiva. A quem seria atribuído o poder final? A quem caberia a decisão última dentro de tal instituição?

Outra demanda kantiana seria a de que os Estados que criassem as regras internacionais também as respeitassem ${ }^{8}$. Contudo, a posição soberana internacional esbarra na ausência de um limite posterior para tal poder. Trata-se, portanto, da última fronteira possível em que a produção de leis pode ser realizada, mas não existe mais, em um mundo pós-metafísico, qualquer Direito que se coloque além do internacional.

8 No projeto de definição das características necessárias para ser alcançada a paz perpétua, Kant (1988) elenca seis artigos preliminares que reduziriam a disposição para realizar a guerra, mas eles, por si próprios, não seriam capazes de estabelecer a paz. Os artigos dispunham a proibição de fazer acordos de paz temporários enquanto planejam guerras futuras, a proibição da anexação de um Estado por outro, a abolição de exércitos permanentes, a recusa de entregar dívidas nacionais para temas externos, a impossibilidade de interferência por um Estado nos assuntos internos de outro, e limites na condução da guerra, reduzindo atos que fomentem a desconfiança. Além disso, Kant apresenta três artigos definitivos para a paz perpétua: 1) cada Estado deve ter uma Constituição republicana, na qual quem decide se a guerra será ou não realizada são os mesmos que pagam o preço por ela, tanto em termos monetários como na própria carne. Estados republicanos seriam, por isso, relutantes em declarar guerra e seriam mais propícios a aceitar negociações, em vez de recorrerem às forças bélicas. Ele acredita que quando os Estados são governados pela vontade do povo, há uma base sólida para a construção de relações pacíficas entre os Estados; 2) cada Estado deve participar de uma União de Estados (como a atual ONU); 3) é necessário um Direito cosmopolita de hospitalidade universal. 
Deus ou o direito natural já não sustentam tal posição. Outra dificuldade se aloja na produção conceitual que fuja da retórica da organização política interna dos Estados, pois, no plano internacional, acaba-se por mimetizar tais categorias em estruturas arrefecidas.

Por fim, é possível dizer que ainda existem Estados "bandidos"? Sim, pois, ainda que a terminologia mude, de "rogue" para "outlaw", a violação da ordem internacional continua a ocorrer dos dois lados, tanto por parte daqueles que afirmam defendê-la como daqueles que são acusados de violá-la. Por isso, em uma última volta, percebe-se que a tarefa da desconstrução deve permanecer, pois o exemplo enfocado, em alguma medida, traçou as linhas de como um nome próprio, em seu desenlace, nunca se refere a apenas um ente.

No caso, são observados entes que, mesmo ocupando posições diametralmente opostas no jogo da globalização, no cenário internacional, podem ser emparelhados por suas atitudes, suas condutas no mundo, podendo ser classificados e nomeados como "bandidos", "rogues", "voyous"; colocados na "rogue's gallery". Mesmo que se use da força (de lei) em nome da democracia, ainda prevalece a máxima: "La raison du plus fort est toujours la meilleure", ou seja, alguma razão, a do mais forte, acaba por ser a melhor, aquela ligada à lei, a qual mantém seu crédito não por ser justa, mas por ser a lei.

\section{Referências}

AGAMBEN, Giorgio. State of exception. Chicago: University of Chicago Press, 2005.

BEARDSWORTH, Richard. Derrida y lo politico. Buenos Aires: Prometeo Libros, 2008.

BEAULAC, Stéphane. The power of language in the making of international law. Leiden: Martinus Nijhoff Publishers, 2004.

BENNINGTON, Geoffrey. Jacques Derrida. Rio de Janeiro: Zahar, 1996. 
CAMBRIDGE INTERNATIONAL DICTIONARY OF ENGLISH. Cambridge: Cambridge University Press, 1995.

BHUTA, Nehal. A global State of exception? The United States and World Order. Constellations, v. 10, n. 3, p. 371-391, 2003.

CAPUTO, John D. Deconstruction in a nutshell. New York: Fordham University Press, 1997.

DERRIDA, Jacques. 0 animal que logo sou (A seguir). São Paulo: UNESP, 2002a.

. The beast \& the sovereign. Chicago: the University of Chicago Press, 2009. v. I.

. Espectros de Marx: El estado de la deuda, el trabajo del duelo y la nueva internacional. Madrid: Trotta, 2003.

. Força de lei: o fundamento místico da autoridade. São Paulo: Martins Fontes, 2007.

. Gramatologia. São Paulo: Perspectiva, 1973.

. Politics of friendship. London: Verso, 1997.

. Rogues. Stanford, California: Stanford University Press, 2005.

. Torres de Babel. Belo Horizonte: UFMG, 2002b.

DICIONÁRIO Garnier da Difel: francês-português. São Paulo: Difel, 1968.

HELLER, Agnes; FÉHER, Ferenc. A condição política pós-moderna. Rio de Janeiro: Civilização Brasileira, 2002.

HOBSBAWM, Eric. Bandidos. Barcelona: Crítica, 2003.

KANT, Immanuel. A paz perpétua e outros opúsculos. Lisboa: Edições 70, 1988.

KOZICKI, Katya. A interpretação do direito e a possibilidade da justiça em Jacques Derrida. In: FONSECA, Ricardo Marcelo. Crítica da modernidade: diálogos com o direito. Florianópolis: Fundação Boiteux, 2005. p. 129-143. 
MOUFFE, Chantal. Carl Schmitt and the paradox of liberal democracy. In: MOUFFE, Chantal. The Challenge of Carl Schmitt. London: Verso, 1999. p.36-59.

NÔVO Michaelis: Inglês-português. 10. ed. São Paulo: Melhoramentos, 1971.

OXFORD Advanced learner's dictionary of current English. Oxford: Oxford University Press, 2005.

RENAN, Ernest. ¿Qué es una nación? Madrid: Alianza, 1987.

RICOEUR, Paul. Sobre la traducción. Buenos Aires: Paidós, 2009.

SKINNER, Anamaria. Espectros de Marx: por que esse plural? In: NASCIMENTO, Evandro; GLENADEL, Paula (Org.). Em torno de Jacques Derrida. Rio de Janeiro: 7Letras, 2000. p. 65-76.

TOCQUEVILLE, Alexis. A democracia na América: leis e costumes de certas leis e certos costumes políticos que foram naturalmente sugeridos aos americanos por seu estado social democrático. São Paulo: Martins Fontes, 1998.

Recebido em: 00/11/13

Aprovado em: 00/12/13 